\title{
Programa Bolsa Família (Pbf): Um Estudo nos Municípios que Integram a Associação dos Municípios da Zona da Produção (Amzop)
}

\section{Family Bag Program (Pbf): A Study In Municipalities Participating Association Of Production Area Municipalities (Amzop)}

\begin{abstract}
Resumo
O estudo teve por objetivo descrever a situação dos municípios de abrangência da AMZOP, em relação ás famílias inscritas no cadastro único para programas sociais do governo federal (CADÚNICO) e beneficiários no recebimento do PBF. Trata-se de um estudo que possui uma abordagem metodológica do tipo quanti-qualitativa e quanto aos objetivos a pesquisa é do tipo descritiva. Os dados primários foram obtidos por meio de entrevistas com os responsáveis do Centro de Referência de Assistência Social dos 42 (quarenta e dois) municípios que integram a AMZOP. Os resultados indicam que 17,79\% dos inscritos no CADÚNICO, possuem renda de até $R \$ 77,00$ por mês, o qual fica dentro de uma faixa de renda definida como de pobreza e extrema pobreza. Em relação ao PBF, os resultados indicam que em 20 municípios sua população apresenta dependência, acima da média nacional de 21,64\%. Estes municípios apresentam o número de beneficiários do PBF, que variam entre $21,65 \%$ a 32,96\% de sua população.
\end{abstract}

Palavras-chave: Programa Bolsa Família, Municípios, AMZOP.

\begin{abstract}
This study aimed to describe the situation of coverage of municipalities AMZOP in relation to the families registered in the single register for social programs of the federal government (CADÚNICO) and beneficiaries receiving the $P B F$. This is a study that has a methodological approach to quantitative and qualitative type and about the research goals is the descriptive. Primary data were obtained through interviews with members of the Social Assistance Reference Center of 42 (forty-two) municipalities of the AMZOP. The results indicate that $17.79 \%$ of respondents in $C A D U ́ N I C O$, have income of up to $R \$ 77.00$ per month, which is within a range defined as income poverty and extreme poverty. Regarding the PBF, the results indicate that in 20 municipalities the population has dependency, above the national average of $21.64 \%$. These municipalities have the number of PBF, ranging from $21.65 \%$ to $32.96 \%$ of its population.
\end{abstract}

Keywords: Bolsa Família Program, municipalities, AMZOP.

Recebido: 09/02/2016 Aceito: 30/06/2016

Lorimar Francisco Munaretto $^{1}$, Juliana De Fátima Da Silva ${ }^{2}$, Jefferson Alves da Costa Junior ${ }^{3}$ e Paulo Henrique Vianna ${ }^{4}$

${ }^{1}$ Universidade Federal de Santa Maria, Frederico Westphalen, Rio Grande do Sul, franciscomunaretto@gmail.com - Rua Campos Elíseos, 468, Bairro Itapajé, Frederico Westphalen - RS - Brasil, CEP 98400.000.

${ }^{2}$ Universidade Federal de Santa Maria - UFSM- julianafatsil@gmail.com.

${ }^{3}$ Professor do Campus da UFSM - Frederico Westphalen - RS

${ }^{4}$ Analista da Tecnologia da Informação - UFSM - Campus de Frederico Westphalen - RS 


\section{Introdução}

Historicamente os pequenos municípios, com predomínio econômico baseado no setor primário, buscam alternativas para modificar seus arranjos produtivos, tendo em vista a diversificação de atividades e maior agregação de valor.

A região de abrangência dos municípios da zona da produção, vinculados a associação dos municípios (AMZOP), é formada por pequenas propriedades rurais, com área média de 20 ha., e a obtenção de rendas decorrem primordialmente por meio de uma safra de soja, milho ou feijão. Este modelo de produção em pequenas propriedades rurais baseada na monocultura vem gradativamente perdendo espaço.

A produção de commodities agrícolas está associada a grandes propriedades rurais, pela capacidade (volume) de produção, o que no caso dos municípios em questão, não encontra respaldo, pois são caracterizados por pequenas propriedades rurais, muito em função do relevo dessas regiões serem em grande parte ondulado, com grande parte dos solos com afloramento de rochas basálticas.

A reduzida área de cultivo e a adoção da monocultura são fatores que afetam a inviabilização das pequenas propriedades rurais, tendo como consequência o abandono das famílias de suas propriedades rurais, passando a residir nas cidades sedes dos municípios ou em centros maiores.

Muitas das famílias rurais que persistem neste modelo e mesmo as que passam a residir nas cidades, em sua maioria ficam na dependência de programas sociais governamentais tendo em vista a sua fragilidade social, econômica, em situação de pobreza e extrema pobreza.

Neste contexto o Programa Bolsa Família (PBF), bem como demais programas operacionalizados pelo Ministério do Desenvolvimento Social e Combate a Fome (MDS), foram instituídos, com os objetivos de estimular a emancipação sustentada das famílias que vivem em situação de pobreza ou extrema pobreza, bem como combater a pobreza (WEISSHEIMER, 2006).

O presente estudo tem por objetivo geral verificar e descrever a situação (posição) dos municípios de abrangência da Associação dos Municípios da Zona da Produção (AMZOP), em relação as famílias inscritas no cadastro único para programas sociais do governo federal
(CADÚNICO) e beneficiários no recebimento do PBF.

Em termos específicos, busca-se: i) verificar a quantidade de famílias cadastradas no CADÚNICO de cada município da AMZOP, ii) identificar a quantidade de famílias beneficiadas pelo PBF, iii) demonstrar o montante de recursos financeiros transferidos ao PBF nos municípios, iv) demonstrar os municípios com maior concentração (número) de famílias em estado de vulnerabilidade social e v) apresentar a relação entre índice de desenvolvimento humano municipal (IDHM) e com o número de famílias beneficiárias do $\mathrm{PBF}$.

A AMZOP é constituída por 42 municípios, localizados na região norte e noroeste do Estado do RS. Estes municípios possuem sua vocação primordialmente voltada no setor primário em atividades realizadas em pequenas propriedades rurais de até 20 hectares, representando cerca de $70 \%$ da economia dos municípios.

\section{Revisão teórica}

Neste capítulo apresentam-se a revisão teórica do estudo. Inicia descrevendo as origens do programa $\mathrm{PBF}$, na segunda seção apresenta os eixos e condicionalidades do PBF, após demonstra o montante de transferências do PBF por regiões e estados do Brasil e por fim os municípios que integram a AMZOP.

\subsection{Origens do PBF}

A política social no Brasil foi instituída como direito a partir da Constituição Federal Brasileira (CFB) de 1988 que no art. $5^{\circ}$ em seu primeiro capítulo assegura que:

Todos são iguais perante a lei, sem distinção de qualquer natureza, garantindo-se aos brasileiros e aos estrangeiros residentes no País a inviolabilidade do direito à vida, à liberdade, à igualdade, à segurança e à propriedade [...].

O artigo 203, da CFB, estabelece que a assistência social será prestada a quem dela necessitar, independentemente de contribuição à seguridade social, e tem por objetivos:

I - a proteção à família, à maternidade, à infância, à adolescência e à velhice; II - o amparo às crianças e adolescentes carentes; III - a promoção da integração ao mercado de trabalho; IV - a habilitação e reabilitação das 
pessoas portadoras de deficiência e a promoção de sua integração à vida comunitária; V - a garantia de um salário mínimo de benefício mensal à pessoa portadora de deficiência e ao idoso que comprovem não possuir meios de prover à própria manutenção ou de tê-la provida por sua família, conforme dispuser a lei.

Já o art. 204 da CFB estabelece sobre as ações governamentais na área da assistência social que serão realizadas com recursos do orçamento da seguridade social, previstos no art. 195, além de outras fontes, e organizadas com base nas seguintes diretrizes:

I - descentralização político-administrativa, cabendo a coordenação e as normas gerais à esfera federal e a coordenação e a execução dos respectivos programas às esferas estadual e municipal, bem como a entidades beneficentes e de assistência social; II - participação da população, por meio de organizações representativas, na formulação das políticas e no controle das ações em todos os níveis.

A partir do previsto na CFB, por meio da Lei Federal $\mathrm{n}^{\mathrm{o}} 10.836$ de 09 de janeiro de 2004, foi criado o PBF, com o objetivo de proporcionar em nível nacional a transferência de renda condicionada a famílias pobres e extremamente pobres.

No ano de 2010, o PBF estava implementado em 5.565 municípios brasileiros e no Distrito Federal desde o ano de 2006, tendo orçamento em torno de um bilhão de reais mensais atendendo a mais de 13 milhões de famílias em todo território nacional (SILVA, 2010, p. 1).

De acordo com Thomé (2013, p.71-72), em 2013, o PBF atendia a cerca de 13,8 milhões de famílias, ou cerca de 50 milhões de pessoas (equivalendo a algo em trono de $27 \%$ da população brasileira); é o quarto maior programa social do país em pessoas assistidas, ficando atrás apenas dos beneficiários do Sistema Único de Saúde (SUS), da Educação e da Previdência Social. Em termos absolutos, é o programa mais amplo do mundo neste gênero.

Cunha (2009, p.331), explica que o PBF possui enquanto "[...] objetivo erradicar a pobreza e a marginalização, reduzindo as desigualdades sociais e regionais $[\ldots]$ ".

$\mathrm{O}$ cadastramento dos beneficiários do $\mathrm{PBF}$ é realizado pelos órgãos municipais de assistência social, por meio de informações inseridas pelo município no CADÚNICO (agente operador), ficando a gerência do programa a cargo do Ministério do Desenvolvimento Social (MDS) e as operações de pagamento sob responsabilidade da Caixa Econômica Federal (LEMOS E RIBEIRO; 2012).

O CADÚNICO, foi criado em 2001, e regulamentado pelo Decreto $\mathrm{n}^{\circ} 6.135 / 07$ e coordenado pelo MDS, com o objetivo de ser utilizado para a seleção de beneficiários e integração de programas sociais do Governo Federal, entre os quais o PBF.

As informações do CADÚNICO podem também ser utilizadas pelos governos estaduais, federais e municipais para obter o diagnóstico socioeconômico das famílias cadastradas, possibilitando a análise das suas principais necessidades, além de permitir que sejam realizados o monitoramento e a avaliação dos efeitos de tais programas na área de assistência social.

O CADÚNICO pode ser utilizado pelas famílias de baixa renda. São consideradas famílias de baixa renda, aquelas com renda igual ou inferior a meio salário mínimo por pessoa (per capita) ou renda mensal de até três salários mínimos. As famílias com renda mensal total superior três salários mínimos só devem ser cadastradas por demanda para programas específicos, como os programas de habitação e saneamento que utilizem os registros do Cadastro Único para a seleção das famílias (MDS, 2015).

De acordo com o MDS (2013), o cadastramento não significa a inclusão imediata no PBF Programa Bolsa Família. Não há prazo fixado para concessão do benefício do Programa Bolsa Família para as famílias cadastradas. Para começar a receber o benefício, a família precisa aguardar que o sistema analise as informações do Cadastro Único para verificar se tem perfil do programa e se o município não atingiu ainda sua meta, ou seja, se ainda há espaço para outras famílias pobres serem beneficiadas.

A ordem de concessão de benefício é a de renda, identificada pelos dados inseridos no sistema pelo setor responsável no município. O governo local efetuará a exclusão do cadastro da família da base local do Cadastro Único apenas e tão somente quando ocorrer: 
I) falecimento de toda a família;

II) recusa da família em prestar informações; ou

III) comprovação de omissão de informações ou prestação de informações falsas pela família e que caracteriza má fé.

Nos casos em que passado o período de dois anos, caso os cadastros não tenham sido atualizados ou revalidados, o governo local (município) poderá excluí-los se, no decorrer dos dois anos subsequentes a família não tiver sido encontrada para atualização ou revalidação do seu cadastro.

Nos casos relacionados aos itens II e III, a exclusão deverá ser realizada após a emissão de parecer social, elaborado e assinado por assistente social do governo local que ateste a ocorrência do motivo da exclusão. $\mathrm{O}$ documento elaborado, ou a cópia, será anexado ao formulário de cadastramento da família e arquivado (MDS, 2015).

O Programa Bolsa Família somente é concedido para as famílias com renda familiar por pessoa de até $\mathrm{R} \$ 140,00$ e a concessão, além de outros fatores, depende de previsão financeira e orçamentária. Enquanto não ocorre a concessão do benefício, as famílias devem manter seus cadastros sempre atualizados (MDS, 2015).
De acordo com Thomé (2013, p.77), as famílias em situação de extrema pobreza recebem um benefício básico de $\mathrm{R} \$ 70,00$, acrescentado o benefício variável de $\mathrm{R} \$ 32,00$ por criança no domicílio e pode chegar a até cinco crianças. Existe ainda um terceiro benefício, vinculado ao adolescente, de $\mathrm{R} \$ 38,00$, que pode atender a até dois jovens. No total, o montante pode chegar aos $\mathrm{R} \$ 306,00$, pouco menos da metade do valor do salário mínimo.

O cadastramento de cada família estará vinculado a um Responsável Familiar - RF, maior de dezesseis anos, preferencialmente mulher. O RF será o responsável pelo recebimento do benefício e cumprimento das condicionalidades de todos os membros da família.

\subsection{Eixos e condicionalidades do PBF}

Os eixos do PBF estão representados por meio da figura 1, que demostra os agentes, os procedimentos e condicionalidades para receber o benefício do PBF.

Figura 1 - Agentes envolvidos no programa bolsa família

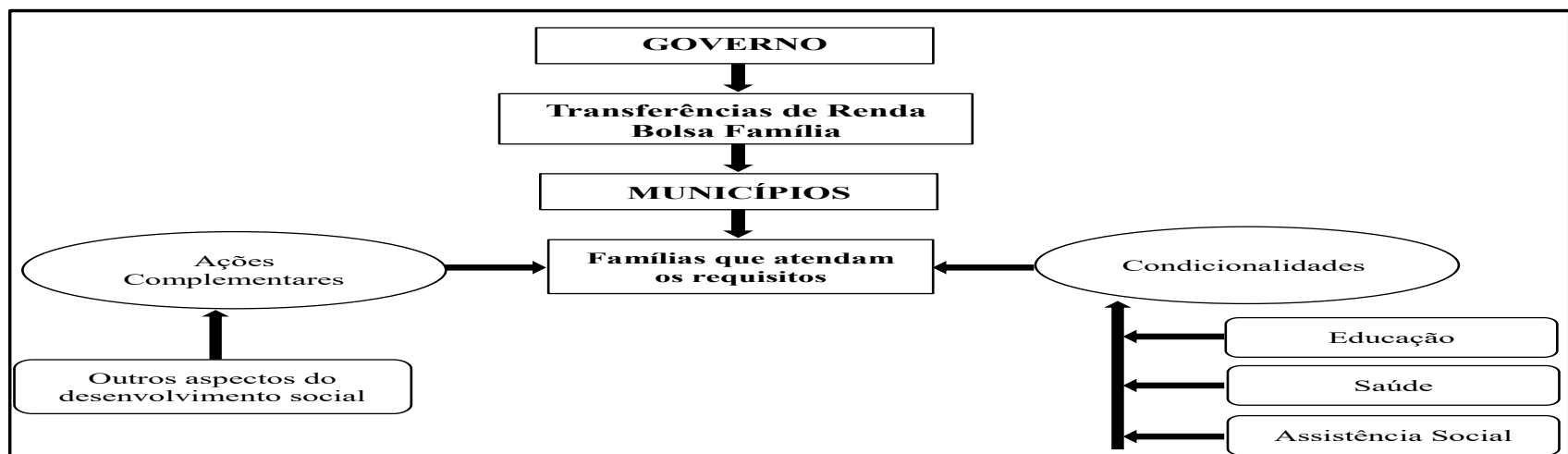

Fonte: Adaptado de Pinto et al. (2010). O programa bolsa família de 2004 a 2010: efeitos do desenvolvimento regional no Brasil e em suas regiões. Qualit@s Revista Eletrônica. Vol.17.nº 1 .

Com o propósito do combate a pobreza, PBF atua dentro de três eixos.

1)Transferência de renda para o alívio imediato da pobreza, encarando esta como uma questão de insuficiência de renda;

2)Condicionalidades para reforçar a estrutura do programa, devido ao caractere multidimensional, da pobreza;

3)Implementação de programas e ações complementares a fim de proporcionar o desenvolvimento das famílias (PINTO, et al;2015).
Os recursos são repassados pelo governo federal as famílias residentes nos munícipios, que atendam aos requisitos exigidos para receber o benefício do PBF. Por outro lado as famílias beneficiárias devem atender as exigências (condicionalidades) do programa. 
O quadro 1 - Área de concentração, condicionalidades/publico alvo e previsão legal PBF.

\begin{tabular}{|c|c|c|}
\hline $\begin{array}{c}\text { Área de } \\
\text { Concentração }\end{array}$ & $\begin{array}{l}\text { Condicionalidades/ } \\
\text { Público Alvo }\end{array}$ & $\begin{array}{c}\text { Previsão } \\
\text { Legal }\end{array}$ \\
\hline Educação & $\begin{array}{l}\text { Crianças de } 06 \text { a } 15 \text { anos de idade devem ter frequência } \\
\text { escolar mensal mínima de } 85 \% \text { da carga horária. Já os } \\
\text { adolescentes de } 16 \text { e } 17 \text { anos devem ter frequência mínima } \\
\text { de } 75 \% \text {. }\end{array}$ & $\begin{array}{l}\text { Lei } \mathrm{n}^{\circ} 10.836 \text { de } 09 \text { de janeiro de } 2004 \text {. } \\
\text { Decreto } \mathrm{n}^{\circ} 5,209 \text {, de } 17 \text { de setembro de } 2004 \text {, } \\
\text { e Portaria } \mathrm{n}^{\mathbf{o}} 251 \text {, de } 12 \text { de dezembro de } 2012 \text {. }\end{array}$ \\
\hline Saúde & $\begin{array}{l}\text { As gestantes e nutrizes devem comparecer às consultas de } \\
\text { pré-natal a assistência ao puerpério. Já as crianças menores } \\
\text { de } 07 \text { anos de idade deverão cumprir o calendário de } \\
\text { vacinação e realizar o acompanhamento do seu crescimento } \\
\text { e desenvolvimento. }\end{array}$ & $\begin{array}{l}\text { Lei } n^{\circ} 10.836 \text { de } 09 \text { de Janeiro de } 2004 \text {; } \\
\text { Decreto } n^{\circ} 5.209 \text {, de } 17 \text { de setembro de } 2004 \text {, } \\
\text { e Portaria } n^{\circ} 251 \text {, de } 12 \text { de dezembro de } 2012 \text {. }\end{array}$ \\
\hline $\begin{array}{l}\text { Assistência } \\
\text { Social }\end{array}$ & $\begin{array}{l}\text { Ás crianças e adolescentes de até } 15 \text { anos de idade, em risco } \\
\text { ou retiradas do trabalho infantil, exige-se a frequência } \\
\text { mínima de } 85 \% \text { da carga horária relativa aos Serviços de } \\
\text { Convivência e Fortalecimento de Vínculos - SCFV. }\end{array}$ & $\begin{array}{l}\text { Portaria MDS } n^{\circ} 666 \text {, de } 28 \text { de dezembro de } \\
\text { 2005; Portaria } n^{\circ} 251 \text {, de } 12 \text { de dezembro de } \\
\text { 2012. }\end{array}$ \\
\hline
\end{tabular}

Fonte: Adaptado de Banco Mundial, MDS (2015).

O não cumprimento das condicionalidades resulta em advertência no primeiro registro de descumprimento e a partir da segunda ocorrência de descumprimento, a família fica sujeita às seguintes sanções:

- Bloqueio do benefício por um mês, no segundo registro de descumprimento;

- Suspensão do benefício por dois meses a partir do terceiro registro de descumprimento, e, reiteradamente, a partir da ocorrência de novos efeitos no benefício por descumprimento;
- Cancelamento do benefício somente após registro no Sistema de Condicionalidades - SICON de que a família foi inserida em serviço sócio assistencial de acompanhamento familiar do município e, cumulativamente.

\subsection{Montante de transferências do PBF por regiões e estados do Brasil}

A tabela 1 apresenta os valores dos repasses de valores no $\mathrm{PBF}$ em relação ao $\mathrm{PIB}$, dos anos de 2004 até o ano de 2014.

Tabela 1 - Repasses de valores ao PBF em relação ao PIB

\begin{tabular}{|c|c|c|c|}
\hline Ano & $\begin{array}{c}\text { Repasses do Bolsa } \\
\text { Família }\end{array}$ & PIB em RS correntes & $\%$ dO PIB \\
\hline 2004 & 5.533 .257 .937 .91 & $1.958 .705 .300 .290,00$ & $0,2825 \%$ \\
\hline 2005 & $6.873 .978 .415,00$ & $2.171 .735 .600 .840,00$ & $0,3165 \%$ \\
\hline 2006 & 8.145 .378 .044 .07 & $2.409 .802 .753 .950,00$ & $0,3380 \%$ \\
\hline 2007 & $9.222 .092 .911,00$ & $2.718 .031 .637 .470,00$ & $0,3393 \%$ \\
\hline 2008 & $10.811 .168 .987,00$ & $3.107 .530 .777 .000,00$ & $0,3479 \%$ \\
\hline 2009 & $12.417 .041 .638,00$ & $3.328 .173 .595 .670,00$ & $0,3731 \%$ \\
\hline 2010 & $14.366 .015 .610,00$ & $3.886 .835 .000 .000,00$ & $0,3696 \%$ \\
\hline 2011 & $17.283 .104 .720,00$ & $4.374 .765 .000 .000,00$ & $0,3951 \%$ \\
\hline 2012 & $20.288 .877 .787,33$ & $4.713 .095 .979 .500,00$ & $0,4305 \%$ \\
\hline 2013 & $24.890 .107 .091,00$ & $5.157 .568 .999 .999,99$ & $0,4826 \%$ \\
\hline 2014 & $27.189 .725 .615,00$ & $5.521 .256 .074 .049,36$ & $0,4925 \%$ \\
\hline
\end{tabular}

Fonte: Adaptado de Pinto et al. (2015). O programa bolsa família de 2004 a 2010: efeitos do desenvolvimento regional no Brasil e em suas regiões. Qualit@s Revista Eletrônica. Vol.17. nº 1.

Denota-se pela tabela 1 , que o montante dos valores de repasses do PBF vem aumentando gradativamente em relação ao Produto Interno Bruto (PIB) brasileiro. No ano de 2004 os repasses do PBF representavam $0,2825 \%$ do PIB, saltando 0,4925\% do PIB no ano de 2014.
Thomé (2013), explica que, o programa passou a atender a mais de $50 \%$ da população dos Estados do Maranhão, Piauí, Ceará, Alagoas, Paraíba e Pernambuco e $40 \%$ da Bahia, Roraima, Acre, Tocantins, Rio Grande do Norte e Sergipe.

A tabela 2 apresenta o aumento dos valores de 
recursos repassados ao $\mathrm{PBF}$, por regiões brasileiras

do ano de 2012 a 2014.

Tabela 2 - Repasses de valores ao PBF por região no Brasil nos anos de 2012 e 2014.

\begin{tabular}{lrrrr}
\hline \multirow{2}{*}{ Região } & \multicolumn{4}{c}{ Valor da Transferência } \\
\cline { 2 - 5 } & \multicolumn{1}{c}{ Valor de 2012 } & \multicolumn{1}{c}{ V } & \multicolumn{1}{c}{ Valor de 2014 } & \multicolumn{1}{c}{ \% } \\
\hline Norte & $2.520 .802 .220,04$ & $12,42 \%$ & $5.844 .364 .215,00$ & $21,49 \%$ \\
Nordeste & $10.404 .419 .244,27$ & $51,28 \%$ & $12.279 .246 .898,00$ & $45,16 \%$ \\
Cento Oeste & $1.070 .765 .557,00$ & $5,28 \%$ & $1.355 .369 .382,00$ & $4,98 \%$ \\
Sudoeste & $4.813 .052 .557,02$ & $23,72 \%$ & $5.971 .153 .744,00$ & $21,96 \%$ \\
Sul & $1.479 .838 .209,00$ & $7,29 \%$ & $1.739 .591 .376,00$ & $6,40 \%$ \\
\hline TOTAL & $\mathbf{2 0 . 2 8 8 . 8 7 7 . 7 8 7 , 3 3}$ & $\mathbf{1 0 0 , 0 0 \%}$ & $\mathbf{2 7 . 1 8 9 . 7 2 5 . 6 1 5 , 0 0}$ & $\mathbf{1 0 0 , 0 0 \%}$ \\
\hline
\end{tabular}

Fonte: Adaptado do Portal de Transparência - Governo Federal (2015)

Denota-se por meio da tabela 2, um aumento expressivo do montante de recursos repassados ao PBF na região norte do Brasil do ano de 2012 para o ano de 2014. No ano de 2012 os valores repassados na região norte representavam $12,42 \%$ do total das transferências de recursos ao PBF do Brasil, passando para 21,49\% no ano de 2014. Nas demais regiões do Brasil se evidenciam reduções nos valores repassados no PBF do ano de $2012 \mathrm{em}$ relação a 2014. A região nordeste é a que recebe a maior fatia de recursos do PBF.

\subsection{Municípios que integram a AMZOP}

A AMZOP possui sua sede no município de Seberi - RS, tem entre suas finalidades de proporcionar á integração política de seus membros, prestando assistência técnica, respeitada a autonomia de cada municipalidade, além de apresentar as metas fins de organizar ações que busquem elevar os padrões de qualidade de vida e bem estar das comunidades, o planejamento e execução de ações visando incrementar as atividades agrícolas e industriais na região, assessoramento na elaboração e execução de planos, programas e projetos relacionados com educação, saúde pública, assistência social, habitação, serviços urbanos, obras públicas, transporte, comunicações, eletrificação, saneamento básico, entre outros.

Os municípios que integram a AMZOP estão localizados na região norte e noroeste do Estado RS. A figura 2 - apresenta a localização geográfica dos municípios que integram a AMZOP.

Figura 2 - Localização geográfica dos municípios que integram a AMZOP.

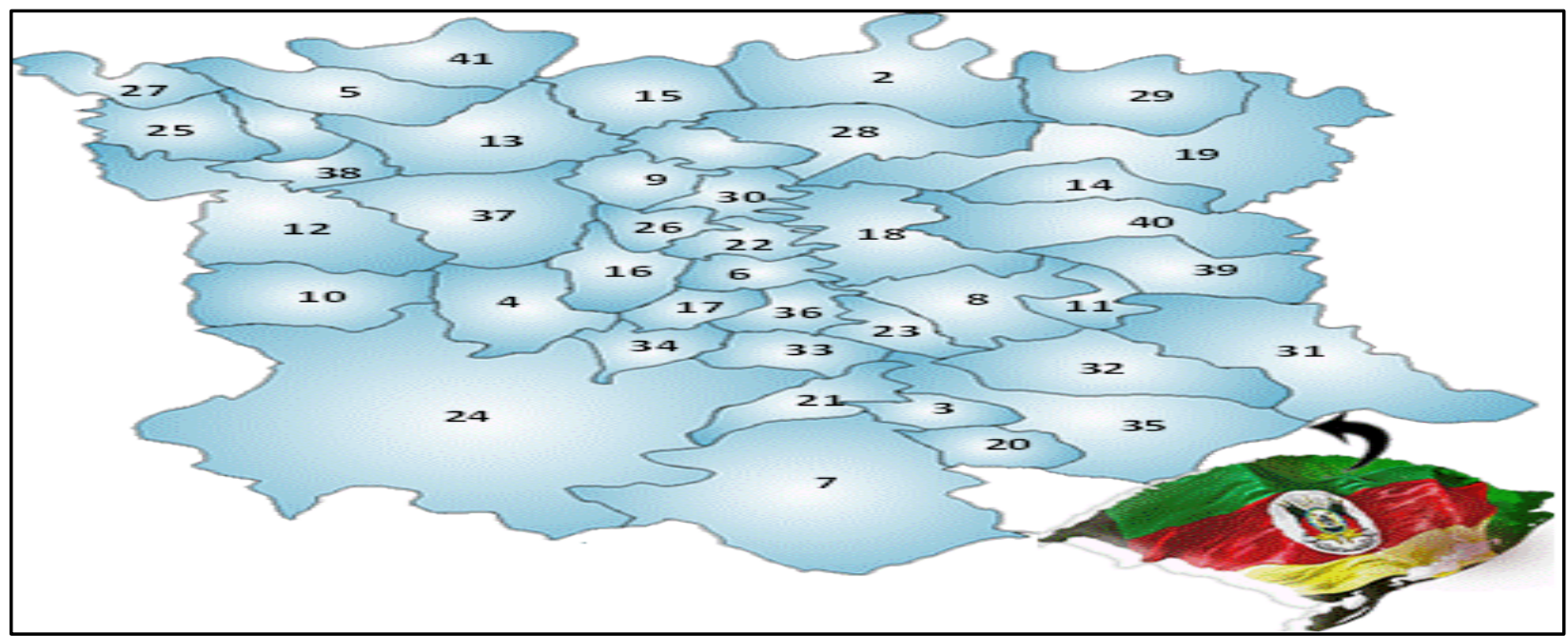

Fonte: Adaptado da AMZOP (2015) - http://www.amzop.com.br/Nossa-Regiao/

O quadro 2 identifica os municípios da AMZOP, apresentados na figura 2.

Quadro 2 - Municípios da AMZOP 


\begin{tabular}{|l|l}
\hline 1.Ametista do Sul & 15.Iraí \\
2.Alpestre & 16.Jaboticaba \\
3.Barra Funda & 17.Lajeado do Bugre \\
4.Boa Vista das Missões & 18.Liberato Salzano \\
5.Caiçara & 19.Nonoai \\
6.Cerro Grande & 20.Nova Boa Vista \\
7.Chapada & 21.Novo Barreiro \\
8.Constantina & 22.Novo Tiradentes \\
9.Cristal do Sul & 23.Novo Xingu \\
10.Dois Irmãos das Missões 11.Engenho & 24.Palmeira das Missões \\
Velho & 25.Palmitinho \\
12.Erval Seco & 26.Pinhal \\
13.Frederico Westphalen & 27.Pinheirinho do Vale \\
14.Gramado dos Loureiros & 28.Planalto \\
\hline
\end{tabular}

Fonte: Elaborado pelo autor

A AMZOP é formada por municípios situados na região norte e noroeste do estado do RS, com população é de 279.023 (IBGE;2010) habitantes. A região é formada por 42 (quarenta e dois) municípios, com predomínio do setor primário e na agroindústria.

\section{Método de estudo}

A pesquisa realizada possui uma abordagem metodológica do tipo quanti-qualitativa. Quanto aos objetivos a pesquisa se classifica como descritiva, pois visa conhecer e descrever sobre a situação dos municípios em relação aos inscritos no CADÚNICO, famílias atendidas no PBF de cada município que integram a AMZOP.

Para Gil (2002), as pesquisas descritivas têm como objetivo primordial a descrição das características de determinada população ou fenômeno ou, então, o estabelecimento de relações entre variáveis. Uma de suas características mais significativas está na utilização de técnicas padronizadas de coleta de dados, tais como o questionário e a observação sistemática.

Quanto aos meios de investigação a pesquisa se caracteriza como levantamento. Para Vergara (1997, p.45), a pesquisa de campo é a investigação empírica realizada no local onde ocorre ou ocorreu um fenômeno ou que dispõe de elementos para explica-los. Pode incluir entrevistas, aplicação de questionários, testes e observação participante ou não.
Os dados primários foram obtidos por meio de entrevistas com os responsáveis do Centro de Referência de Assistência Social (CRAS) dos 42 (quarenta e dois) municípios que integram a AMZOP, com perguntas abertas e também por meio de informações disponibilizadas no site do Ministério do Desenvolvimento Social (MDS).

No site do MDS, foi possível obter os valores desembolsados pelo Governo Federal em relação ao $\mathrm{PBF}, \mathrm{n}^{\mathrm{o}}$ de famílias dependentes do programa de cada Município objeto do estudo, dos Estados e da União entre outros. Já os dados secundários foram obtidos por meio de bibliografias e legislações que tratam sobre o assunto.

Os resultados foram apresentados por meio de tabelas, quadros, com os comentários e conclusões, individuais e de forma consolidada dos 42 (quarenta e dois) municípios. Também foi realizada a comparação dos resultados dos 42 municípios, com os valores percentuais do estado do RS, com os estados de Santa Catarina e Paraná e do Brasil.

\section{Apresentação e análise dos resultados}

$\mathrm{Na}$ sequência apresentam-se os resultados do estudo, por meio das seguintes seções; ranqueamento dos municípios da AMZOP em relação aos inscritos no CADÚNICO, após descreve-se sobre os beneficiários do PBF de todos os Municípios da AMZOP e por fim a relação estatística de famílias beneficiadas pelo PBF em relação ao IDHM. 


\subsection{Ranqueamento dos municípios da AMZOP no CADÚNICO.}

Tabela 3- Relação dos municípios com o número de pessoas cadastradas no CADÚNICO/mês de abril de 2015.

\begin{tabular}{|c|c|c|c|c|}
\hline Posição & Municípios & $\begin{array}{l}\text { População } \\
\text { IBGE/2010 }\end{array}$ & $\begin{array}{l}\text { Pessoas Cadastradas } \\
\text { CADÚNICO }(\mathrm{abr} / 15)\end{array}$ & $\begin{array}{c}\text { \% da } \\
\text { População }\end{array}$ \\
\hline 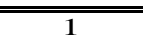 & Cristal do Sul & 2826 & 2.011 & $71,16 \%$ \\
\hline 2 & Engenho Velho & 1530 & 1.048 & $68,50 \%$ \\
\hline 3 & Gramado dos Loureiros & 2269 & 1.536 & $67,70 \%$ \\
\hline 4 & Ametista do Sul & 7323 & 4.768 & $65,11 \%$ \\
\hline 5 & Lajeado do Bugre & 2487 & 1.597 & $64,21 \%$ \\
\hline 6 & São Pedro das Missões & 1886 & 1.191 & $63,15 \%$ \\
\hline 7 & Cerro Grande & 2417 & 1.519 & $62,85 \%$ \\
\hline 8 & Dois Irmãos das Missões & 2157 & 1.351 & $62,63 \%$ \\
\hline 9 & Jaboticaba & 4111 & 2.541 & $61,81 \%$ \\
\hline 10 & Erval Seco & 7878 & 4.718 & $59,89 \%$ \\
\hline 11 & Trindade do Sul & 5787 & 3.457 & $59,74 \%$ \\
\hline 12 & Três Palmeiras & 4381 & 2.538 & $57,93 \%$ \\
\hline 13 & Nonoai & 12076 & 6.992 & $57,90 \%$ \\
\hline 14 & São José das Missões & 2720 & 1.563 & $57,46 \%$ \\
\hline 15 & Iraí & 8078 & 4.630 & $57,32 \%$ \\
\hline 16 & Pinhal & 2515 & 1.415 & $56,26 \%$ \\
\hline 17 & Sagrada Familia & 2595 & 1.431 & $55,14 \%$ \\
\hline 18 & Planalto & 10524 & 5.771 & $54,84 \%$ \\
\hline 19 & Seberi & 10902 & 5.926 & $54,36 \%$ \\
\hline 20 & Pinheirinho do Vale & 4503 & 2.384 & $52,94 \%$ \\
\hline 21 & Rio dos índios & 3616 & 1.886 & $52,16 \%$ \\
\hline 22 & Liberato Salzano & 5780 & 2.990 & $51,73 \%$ \\
\hline 23 & Novo Barreiro & 3978 & 2.056 & $51,68 \%$ \\
\hline 24 & Novo Xingu & 1757 & 900 & $51,22 \%$ \\
\hline 25 & Boa Vista das Missões & 2114 & 1.070 & $50,61 \%$ \\
\hline 26 & Novo Tiradentes & 2277 & 1.132 & $49,71 \%$ \\
\hline 27 & Rodeio Bonito & 5743 & 2.756 & $47,99 \%$ \\
\hline 28 & Vicente Dutra & 5285 & 2.520 & $47,68 \%$ \\
\hline 29 & Palmitinho & 6920 & 3.187 & $46,05 \%$ \\
\hline 30 & Ronda Alta & 10228 & 4.629 & $45,26 \%$ \\
\hline 31 & Taquaruçu do Sul & 2970 & 1.298 & $43,70 \%$ \\
\hline 32 & Palmeira das Missões & 34335 & 14.887 & $43,36 \%$ \\
\hline 33 & Vista Alegre & 2832 & 101.185 & $4 \overline{41,84 \%}$ \\
\hline 34 & Barra Funda & 2367 & 984 & $41,57 \%$ \\
\hline 35 & Alpestre & 8027 & 3.163 & $39,40 \%$ \\
\hline 36 & Caiçara & 5071 & 1.982 & $39,08 \%$ \\
\hline 37 & Constantina & 9741 & 3.367 & $34,57 \%$ \\
\hline 38 & Sarandi & 21312 & 6.772 & $31,78 \%$ \\
\hline 39 & Chapada & 9377 & 2.801 & $29,87 \%$ \\
\hline 40 & Frederico Westphalen & 28848 & 8.522 & $29,54 \%$ \\
\hline 41 & Rondinha & 5520 & 1.395 & $25,27 \%$ \\
\hline \multirow[t]{6}{*}{42} & Nova Boa Vista & 1960 & 312 & $15,92 \%$ \\
\hline & TOTAL & 279.023 & 128.181 & $45,94 \%$ \\
\hline & SANTA CATARINA & 6.249 .682 & 1.413.987 & $22,62 \%$ \\
\hline & PARANÁ & 10.439 .601 & 3.649 .706 & $34,96 \%$ \\
\hline & RIO GRANDE DO SUL & 10.695 .532 & 3.152 .687 & $29,48 \%$ \\
\hline & BRASIL & 190.732 .694 & 81.811 .228 & $42,89 \%$ \\
\hline
\end{tabular}

Fonte: Dados da pesquisa.

Os resultados da pesquisa indicam que, dos 42 (quarenta e dois) municípios que integram a AMZOP, 32 (trinta e dois) apresentam percentual de inscritos no CADÚNICO, para programas sociais do governo, acima da média nacional de $42,89 \%$. O município de Cristal do Sul é o que possui o maior número de inscritos, no CADÚNICO em relação a sua população. Em termos relativos o município de Cristal do Sul possui $71,16 \%$ da população inscrita no CADÚNICO.
Já o município de Nova Boa Vista, possui apenas $15,92 \%$ de sua população inscrita no CADÚNICO. Os resultados demonstram que no mês de abril, os municípios da região da AMZOP, possuíam 128.181 pessoas inscritas no CADÚNICO, representando $45,94 \%$ da população da região, o que está acima da média dos três estados da região Sul e do Brasil. Isso sinaliza que a busca por programas sociais em especial o PBF, decorre primordialmente da falta de alternativas de geração de trabalho e renda e de sinais de gradativo empobrecimento de muitos municípios desta região. 
Tabela 4 - Pessoas inscritas no CADÚNICO e renda per capita.

\begin{tabular}{|c|c|c|c|c|c|c|c|c|c|c|c|c|}
\hline & \multirow{2}{*}{ Municípios } & \multirow{2}{*}{$\begin{array}{c}\text { População IBGE } \\
\text { IBGE/2010 }\end{array}$} & \multirow{2}{*}{$\begin{array}{c}\text { Pessoas Cadúnico } \\
\text { Cadastro (04/15) }\end{array}$} & \multirow{2}{*}{$\begin{array}{c}\% \\
\text { População } \\
\end{array}$} & \multicolumn{2}{|c|}{ Renda de até 77,00} & \multicolumn{2}{|c|}{ De $>77,01$ até 154} & \multicolumn{2}{|c|}{ De 154,01 até 394,00} & \multicolumn{2}{|c|}{ Acima de 394,00} \\
\hline & & & & & Pessoas & $\%$ & Pessoas & $\%$ & Pessoas & $\%$ & Pessoas & $\%$ \\
\hline 1 & Lajeado do Bugre & 2487 & 1597 & $\begin{array}{l}64,21 \% \\
\end{array}$ & 1031 & $41,5 \%$ & 153 & $6,2 \%$ & 302 & 12,1\% & 10111 & $4,5 \%$ \\
\hline 2 & Cristal do Sul & 2826 & 2011 & $71,16 \%$ & 1053 & $37,3 \%$ & 269 & $9,5 \%$ & 367 & $13,0 \%$ & 322 & $11,4 \%$ \\
\hline 3 & Gramado dos Loureiros & 2269 & 1536 & $67,70 \%$ & 832 & $36,7 \%$ & 212 & $9,3 \%$ & 316 & $13,9 \%$ & 176 & $7,8 \%$ \\
\hline 4 & Trindade do Sul & 5787 & 3457 & $59,74 \%$ & 2100 & $36,3 \%$ & 474 & $8,2 \%$ & 577 & $10,0 \%$ & 306 & $5,3 \%$ \\
\hline 5 & Engenho Velho & 1530 & 1048 & $68,50 \%$ & 553 & $36,1 \%$ & 110 & $7,2 \%$ & 209 & $13,7 \%$ & 176 & $11,5 \%$ \\
\hline 6 & São José das Missões & 2720 & 1563 & $57,46 \%$ & 934 & $34,3 \%$ & 154 & $5,7 \%$ & 292 & $10,7 \%$ & 183 & $6,7 \%$ \\
\hline 7 & Seberi & 10902 & 5926 & $54,36 \%$ & 3693 & $33,9 \%$ & 720 & $6,6 \%$ & 843 & $7,7 \%$ & 670 & $6,1 \%$ \\
\hline 8 & Jaboticaba & 4111 & 2541 & $61,81 \%$ & 1327 & $32,3 \%$ & 392 & $9,5 \%$ & 474 & $11,5 \%$ & 348 & $8,5 \%$ \\
\hline 9 & São Pedro das Missões & 1886 & 1191 & $63,15 \%$ & 569 & $30,2 \%$ & 148 & $7,8 \%$ & 263 & $13,9 \%$ & 211 & $11,2 \%$ \\
\hline 10 & Palmitinho & 6920 & 3187 & $46,05 \%$ & 2055 & $29,7 \%$ & 476 & $6,9 \%$ & 511 & $7,4 \%$ & 145 & $2,1 \%$ \\
\hline 11 & Pinheirinho do Vale & 4503 & 2384 & $52,94 \%$ & 1288 & $28,6 \%$ & 271 & $6,0 \%$ & 519 & $11,5 \%$ & 306 & $6,8 \%$ \\
\hline 12 & Novo Tiradentes & 2277 & 1132 & $49,71 \%$ & 643 & $28,2 \%$ & 70 & $3,1 \%$ & 220 & $9,7 \%$ & 199 & $8,7 \%$ \\
\hline 13 & Rio dos índios & 3616 & 1886 & $52,16 \%$ & 985 & $27,2 \%$ & 356 & $9,8 \%$ & 311 & $8,6 \%$ & 234 & $6,5 \%$ \\
\hline 14 & Ametista do Sul & 7323 & 4768 & $65,11 \%$ & 1991 & $27,2 \%$ & 1177 & $16,1 \%$ & 1120 & $15,3 \%$ & 480 & $6,6 \%$ \\
\hline 15 & Iraí & 8078 & 4630 & $57,32 \%$ & 2117 & $26,2 \%$ & 950 & $11,8 \%$ & 848 & $10,5 \%$ & 715 & $8,9 \%$ \\
\hline 16 & Cerro Grande & 2417 & 1519 & $62,85 \%$ & 631 & $26,1 \%$ & 217 & $9,0 \%$ & 390 & $16,1 \%$ & 281 & $11,6 \%$ \\
\hline 17 & Liberato Salzano & 5780 & 2990 & $51,73 \%$ & 1399 & $24,2 \%$ & 504 & $8,7 \%$ & 765 & $13,2 \%$ & 322 & $5,6 \%$ \\
\hline 18 & Sagrada Familia & 2595 & 1431 & $55,14 \%$ & 597 & $23,0 \%$ & 203 & $7,8 \%$ & 445 & $17,1 \%$ & 186 & $7,2 \%$ \\
\hline 19 & Erval Seco & 7878 & 4718 & $59,89 \%$ & 1787 & $22,7 \%$ & 948 & $12,0 \%$ & 1125 & $14,3 \%$ & 858 & $10,9 \%$ \\
\hline 20 & Vicente Dutra & 5285 & 2520 & $47,68 \%$ & 1179 & $22,3 \%$ & 515 & $9,7 \%$ & 542 & $10,3 \%$ & 284 & $5,4 \%$ \\
\hline 21 & Nonoai & 12076 & 6992 & $57,90 \%$ & 2336 & $19,3 \%$ & 1639 & $13,6 \%$ & 1683 & $13,9 \%$ & 1334 & $11,0 \%$ \\
\hline 22 & Planalto & 10524 & 5771 & $54,84 \%$ & 2019 & $19,2 \%$ & 1279 & $12,2 \%$ & 1600 & $15,2 \%$ & 873 & $8,3 \%$ \\
\hline 23 & Três Palmeiras & 4381 & 2538 & $57,93 \%$ & 801 & $18,3 \%$ & 418 & $9,5 \%$ & 645 & $14,7 \%$ & 674 & $15,4 \%$ \\
\hline 24 & Dois Irmãos das Missões & 2157 & 1351 & $62,63 \%$ & 377 & $17,5 \%$ & 199 & $9,2 \%$ & 405 & $18,8 \%$ & 370 & $17,2 \%$ \\
\hline 25 & Rodeio Bonito & 5743 & 2756 & $47,99 \%$ & 949 & $16,5 \%$ & 277 & $4,8 \%$ & 863 & $15,0 \%$ & 667 & $11,6 \%$ \\
\hline 26 & Ronda Alta & 10228 & 4629 & $45,26 \%$ & 1676 & $16,4 \%$ & 894 & $8,7 \%$ & 1348 & $13,2 \%$ & 711 & $7,0 \%$ \\
\hline 27 & Boa Vista das Missões & 2114 & 1070 & $50,61 \%$ & 330 & $15,6 \%$ & 175 & $8,3 \%$ & 318 & $15,0 \%$ & 247 & $11,7 \%$ \\
\hline 28 & Caiçara & 5071 & 1982 & $39,08 \%$ & 707 & $13,9 \%$ & 326 & $6,4 \%$ & 435 & $8,6 \%$ & 514 & $10,1 \%$ \\
\hline 29 & Palmeira das Missões & 34335 & 14887 & $43,36 \%$ & 4530 & $13,2 \%$ & 3957 & $11,5 \%$ & 4596 & $13,4 \%$ & 1804 & $5,3 \%$ \\
\hline 30 & Sarandi & 21312 & 6772 & $31,78 \%$ & 2784 & $13,1 \%$ & 1498 & $7,0 \%$ & 1732 & $8,1 \%$ & 758 & $3,6 \%$ \\
\hline 31 & Novo Barreiro & 3978 & 2056 & $51,68 \%$ & 486 & $12,2 \%$ & 347 & $8,7 \%$ & 685 & $17,2 \%$ & 538 & $13,5 \%$ \\
\hline 32 & Pinhal & 2515 & 1415 & $56,26 \%$ & 255 & $10,1 \%$ & 107 & $4,3 \%$ & 344 & $13,7 \%$ & 709 & $28,2 \%$ \\
\hline 33 & Frederico Westphalen & 28848 & 8522 & $29,54 \%$ & 2921 & $10,1 \%$ & 2147 & $7,4 \%$ & 2653 & $9,2 \%$ & 801 & $2,8 \%$ \\
\hline 34 & Taquaruçu do Sul & 2970 & 1298 & $43,70 \%$ & 281 & $9,5 \%$ & 98 & $3,3 \%$ & 411 & $13,8 \%$ & 508 & $17,1 \%$ \\
\hline 35 & Vista Alegre & 2832 & 1185 & $41,84 \%$ & 230 & $8,1 \%$ & 190 & $6,7 \%$ & 397 & $14,0 \%$ & 368 & $13,0 \%$ \\
\hline 36 & Novo Xingu & 1757 & 900 & $51,22 \%$ & 128 & $7,3 \%$ & 142 & $8,1 \%$ & 266 & $15,1 \%$ & 364 & $20,7 \%$ \\
\hline 37 & Constantina & 9741 & 3367 & $34,57 \%$ & 698 & $7,2 \%$ & 763 & $7,8 \%$ & 963 & $9,9 \%$ & 943 & $9,7 \%$ \\
\hline 38 & Alpestre & 8027 & 3163 & $39,40 \%$ & 538 & $6,7 \%$ & 477 & $5,9 \%$ & 1187 & $14,8 \%$ & 961 & $12,0 \%$ \\
\hline 39 & Rondinha & 5520 & 1395 & $25,27 \%$ & 308 & $5,6 \%$ & 214 & $3,9 \%$ & 280 & $5,1 \%$ & 593 & $10,7 \%$ \\
\hline 40 & Chapada & 9377 & 2801 & $29,87 \%$ & 411 & $4,4 \%$ & 336 & $3,6 \%$ & 959 & $10,2 \%$ & 1095 & $11,7 \%$ \\
\hline 41 & Nova Boa Vista & 1960 & 312 & $15,92 \%$ & 79 & $4,0 \%$ & 18 & $0,9 \%$ & 81 & $4,1 \%$ & 134 & $6,8 \%$ \\
\hline \multirow[t]{6}{*}{42} & Barra Funda & 2367 & 984 & $41,57 \%$ & 22 & $0,9 \%$ & 32 & $1,4 \%$ & 262 & $11,1 \%$ & 668 & $28,2 \%$ \\
\hline & TOTAL & 279.023 & 128.181 & $45,94 \%$ & 49630 & 17,79\% & 23852 & $8,55 \%$ & 32552 & $11,67 \%$ & 222147 & $7,94 \%$ \\
\hline & SANTA CATARINA & 6.249 .682 & 1.413 .987 & $22,62 \%$ & 335183 & $5,36 \%$ & 318425 & $5,10 \%$ & 478839 & $7,66 \%$ & 281540 & $4,50 \%$ \\
\hline & PARANA & 10.439 .601 & 3.649 .706 & $34,96 \%$ & 864024 & $8,28 \%$ & 850137 & $8,14 \%$ & 1350905 & $12,94 \%$ & 584640 & $5,60 \%$ \\
\hline & RIO GRANDE DO SUL & 10.695 .532 & 3.152 .687 & $29,48 \%$ & 1144354 & $10,70 \%$ & 696028 & $6,51 \%$ & 853258 & $7,98 \%$ & 459047 & $4,29 \%$ \\
\hline & BRASIL & 190.732 .694 & 81.811 .228 & $42,89 \%$ & 42094162 & $22,07 \%$ & 15469472 & $8,11 \%$ & 17555979 & $9,20 \%$ & 6691615 & $3,51 \%$ \\
\hline
\end{tabular}

RGC, Santa Maria, v.3, n.5, Págs. 15-26, jul./dez. 2016 
A tabela 4 apresenta o número de pessoas inscritas no CADÚNICO, e as faixas de rendas mensais per capita. Os resultados demonstram que $17,79 \%$ das pessoas inscritas no CADÚNICO, possuem renda de até $\mathrm{R} \$ 77,00$ por mês, $8,55 \%$ dos inscritos possuem renda de $\mathrm{R} \$ 77,01$ até $\mathrm{R} \$ 154,00$, $11,67 \%$ possuem renda de $\mathrm{R} \$ 154,01$ até $\mathrm{R} \$ 394,00$ e 7,94\% possuem renda acima de $\mathrm{R} \$ 394,00$ por mês.

O município de Lajeado do Bugre é o que apresenta o maior número de inscritos em termos relativos no CADÚNICO, com renda de até R\$ 77,00, (41,50\%), seguido do município de Cristal do Sul $(37,30 \%)$. Percebe-se pelos resultados que dos 42 (quarenta e dois) municípios que integram a AMZOP, 20 (vinte), apresentam percentual de inscritos no CADÚNICO, com renda de até $\mathrm{R} \$$ 77,00 por mês está acima da média do Brasil de $22,07 \%$.

\subsection{Beneficiários do Programa Bolsa Família nos Municípios da AMZOP.}

A tabela 5 apresenta a divisão dos estratos de população dos municípios da AMZOP, em escalas, o número de beneficiários do programa Bolsa Família e o coeficiente da população.

Tabela 5 - Número de município, população, famílias e beneficiários do PBF e coeficiente de famílias e população.

\begin{tabular}{|c|c|c|c|c|c|}
\hline \multirow[b]{2}{*}{ Municípios } & \multicolumn{4}{|c|}{ Estratos de população } & \\
\hline & $\begin{array}{r}\text { Até } 5000 \\
\text { habitantes } \\
\end{array}$ & $\begin{array}{c}\text { De } 5001 \text { até } \\
10000\end{array}$ & $\begin{array}{c}\text { De } 10001 \text { até } \\
20000 \\
\end{array}$ & $\begin{array}{c}\text { De } 20001 \text { até } \\
50000 \\
\end{array}$ & \\
\hline Número de municípios & 22 & 13 & 4 & 3 & 42 \\
\hline População/Habitantes (IBGE; 2010) & 60268 & 90530 & 43730 & 84495 & 279023 \\
\hline Famílias Beneficiárias do PBF & 4542 & 5791 & 3361 & 3735 & 17429 \\
\hline Coeficiente de famílias & $7,54 \%$ & $6,40 \%$ & $7,69 \%$ & $4,42 \%$ & $6,25 \%$ \\
\hline Número de Beneficiários PBF & 12645 & 16068 & 9087 & 10787 & 48587 \\
\hline Coeficiente da população & $20,98 \%$ & $17,75 \%$ & $20,78 \%$ & $12,77 \%$ & $17,41 \%$ \\
\hline
\end{tabular}

Fonte: Dados da pesquisa

De acordo com os dados do IBGE (2010), os 42 (quarenta e dois) municípios que integram a AMZOP, no ano de 2010, apresentam uma população de 279.023 habitantes, destes 1729 famílias com 48.587 beneficiários do PBF.

Ao analisar os estratos da população, denota-se que nos municípios de até 20.000 habitantes o percentual de beneficiários do PBF, é de $17,75 \%$ até
20,98\% da população. Já nos municípios com mais de 20.000 habitantes o número de beneficiários do PBF reduz para $12,77 \%$ da população.

A tabela 6 apresenta o detalhamento dos 42 municípios da AMZOP, com a população IBGE, famílias beneficiadas pelo $\mathrm{PBF}, \mathrm{n}^{\circ}$ de pessoas beneficiadas no $\mathrm{PBF}$, valores dos benefícios e benefício médio per capita. 
Tabela 6

Municípios, população IBGE, famílias beneficiadas pelo PBF, $\mathrm{n}^{\circ}$ de pessoas beneficiadas no PBF, valores dos benefícios e benefício médio do mês de julho de 2015 .

\begin{tabular}{|c|c|c|c|c|c|c|c|}
\hline & Municípios & $\begin{array}{c}1 \\
\text { População } \\
\text { IBGE/2010 }\end{array}$ & $\begin{array}{c}\mathbf{2} \\
\begin{array}{c}\text { Famílias beneficiadas } \\
\text { jul/2015 } \mathrm{p} / \mathrm{PBF}\end{array} \\
\end{array}$ & \begin{tabular}{|c|}
$\mathbf{3}$ \\
Pessoas beneficiadas \\
pelo PBF (População)
\end{tabular} & $\begin{array}{c}\mathbf{4}=\mathbf{3} / \mathbf{1} \\
\begin{array}{c}\text { de Pessoas } \\
\text { beneficiadas pelo } \mathrm{PBF}\end{array}\end{array}$ & \begin{tabular}{|c|}
5 \\
Valor do \\
Benefício RS \\
\end{tabular} & $\begin{array}{c}\mathbf{6 = 5 / 2} \\
\text { Benefício } \\
\text { Médio/família } \\
\end{array}$ \\
\hline 1 & Jaboticaba & 4111 & 507 & 1355 & $32,96 \%$ & $67.172,00$ & 132,49 \\
\hline 2 & Lajeado do Bugre & 2487 & 262 & 778 & $31,27 \%$ & $36.806,00$ & 140,48 \\
\hline 3 & Engenho Velho & 1530 & 135 & 457 & $29,89 \%$ & $37.292,00$ & 276,24 \\
\hline 4 & Cristal do Sul & 2826 & 336 & 844 & $29,87 \%$ & $43.854,00$ & 130,52 \\
\hline 5 & Gramado dos Loureiros & 2269 & 234 & 670 & $29,51 \%$ & $38.696,00$ & 165,37 \\
\hline 6 & Ametista do Sul & 7.323 & 704 & 2077 & $28,37 \%$ & $98.052,00$ & 139,28 \\
\hline 7 & Iraí & 8078 & 858 & 2160 & $26,73 \%$ & $125.696,00$ & 146,50 \\
\hline 8 & Trindade do Sul & 5787 & 559 & 1542 & $26,64 \%$ & $87.536,00$ & 156,59 \\
\hline 9 & São José das Missões & 2720 & 244 & 722 & $26,53 \%$ & $34.651,00$ & 142,01 \\
\hline 10 & Rio dos índios & 3616 & 369 & 946 & $26,15 \%$ & $51.903,00$ & 140,66 \\
\hline 11 & Cerro Grande & 2417 & 212 & 625 & $25,87 \%$ & $35.803,00$ & 168,88 \\
\hline 12 & São Pedro das Missões & 1886 & 157 & 462 & $24,52 \%$ & $23.298,00$ & 148,39 \\
\hline 13 & Sagrada Familia & 2595 & 225 & 623 & $24,00 \%$ & $30.208,00$ & 134,26 \\
\hline 14 & Erval Seco & 7878 & 699 & 1860 & $23,61 \%$ & $104.092,00$ & 148,92 \\
\hline 15 & $\begin{array}{l}\text { Planalto } \\
\text { Plo }\end{array}$ & 10524 & 845 & 2474 & $23,51 \%$ & $119.961,00$ & 141,97 \\
\hline 16 & Vicente Dutra & 5285 & 414 & 1230 & $23,27 \%$ & $69.803,00$ & 168,61 \\
\hline 17 & Pinheirinho do Vale & 4503 & 362 & 1021 & $22,67 \%$ & $54.991,00$ & 151,91 \\
\hline 18 & Seberi & 10902 & 997 & 2456 & $22,53 \%$ & $164.107,00$ & 164,60 \\
\hline 19 & Palmitinho & 6920 & 496 & 1527 & $22,07 \%$ & $81.316,00$ & 163,94 \\
\hline 20 & Dois Irmãos das Missões & 2157 & 177 & 467 & $21,65 \%$ & $24.699,00$ & 139,54 \\
\hline$\overline{21}$ & Novo Tiradentes & 22277 & 1777 & 485 & 21,29\% & $29.907,00$ & "168,97 \\
\hline 22 & Liberato Salzano & 5780 & 400 & 1178 & $20,37 \%$ & $60.359,00$ & 150,90 \\
\hline 23 & Três Palmeiras & 4381 & 324 & 877 & $20,02 \%$ & $50.344,00$ & 155,38 \\
\hline 24 & Nonoai & 12076 & 901 & 2333 & $19,32 \%$ & $128.528,00$ & 142,65 \\
\hline 25 & Novo Barreiro & 3978 & 257 & 741 & $18,63 \%$ & $31.839,00$ & 123,89 \\
\hline 26 & Ronda Alta & 10228 & 618 & 1824 & $17,83 \%$ & $101.856,00$ & 164,82 \\
\hline 27 & Boa Vista das Missões & 2114 & 129 & 375 & $17,75 \%$ & $18.712,00$ & 145,05 \\
\hline 28 & Palmeira das Missões & 34335 & 1.985 & 5656 & $16,47 \%$ & $260.001,00$ & 130,98 \\
\hline 29 & Pinhal & 2515 & 126 & 351 & $13,96 \%$ & $18.038,00$ & 143,16 \\
\hline 30 & Rodeio Bonito & 5743 & 276 & 760 & $13,24 \%$ & $36.999,00$ & 134,05 \\
\hline 31 & Caiçara & 5071 & 266 & 670 & $13,21 \%$ & $34.415,00$ & 129,38 \\
\hline 32 & Vista Alegre & 2832 & 128 & 346 & $12,22 \%$ & $16.417,00$ & 128,26 \\
\hline 33 & Alpestre & 8027 & 340 & 915 & $11,40 \%$ & $43.044,00$ & 126,60 \\
\hline 34 & Constantina & 9741 & 396 & 1047 & $10,75 \%$ & $52.984,00$ & 133,80 \\
\hline 35 & Frederico Westphalen & 28848 & 1.032 & 3073 & $10,65 \%$ & $151.347,00$ & 146,65 \\
\hline 36 & Sarandi & 21312 & 718 & 2055 & $9,64 \%$ & $112.504,00$ & 156,69 \\
\hline 37 & Taquaruçu do Sul & 2970 & 93 & 264 & $8,90 \%$ & $12.873,00$ & 138,42 \\
\hline 38 & Novo Xingu & 1757 & 55 & 145 & $8,26 \%$ & $7.408,00$ & 134,69 \\
\hline 39 & Rondinha & 5520 & 138 & 418 & $7,57 \%$ & $19.986,00$ & 144,83 \\
\hline 40 & Chapada & 9377 & 245 & 686 & $7,31 \%$ & $36.213,00$ & 147,81 \\
\hline 41 & Nova Boa Vista & 1960 & 20 & 55 & $2,82 \%$ & $2.841,00$ & 142,05 \\
\hline \multirow[t]{6}{*}{42} & Barra Funda & 2367 & 13 & 36 & $1,54 \%$ & $1.592,00$ & 122,46 \\
\hline & SOMA MUNICÍPIOS & 279023 & 17429 & 48587 & 17,41\% & $2.558 .143,00$ & 146,78 \\
\hline & SANTA CATARINA & 6.249 .682 & 133.667 & 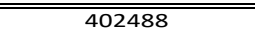 & (6,44\% & 20.423.524,00 & 152,79 \\
\hline & PARANÁ & 10.439 .601 & 391.904 & 1169470 & $11,20 \%$ & $56.581 .001,00$ & 144,37 \\
\hline & RIO GRANDE DO SUL & 10.695 .532 & 416.333 & 1180945 & $11,04 \%$ & 64.034.371,00 & 153,81 \\
\hline & BRASIL & 190.732 .694 & 13.716 .766 & 41272519 & $21,64 \%$ & $2.301 .404 .544,00$ & 167,78 \\
\hline
\end{tabular}

Fonte: Dados da pesquisa

RGC, Santa Maria, v.3, n.5, Págs. 15-26, jul./dez. 2016 
Os resultados demonstram que em termos percentuais o município de Jaboticaba é o que possui o maior número de famílias e habitantes atendidas pelo $\mathrm{PBF}$ em relação a sua população. São 507 famílias que, com 1355 pessoas beneficiadas, que representa o percentual de $32,96 \%$ da população do município. Por outro lado no município de Barra Funda, no mês de julho de 2015, apenas 13 famílias foram beneficiadas pelo PBF, (36 pessoas), o que representa $1,54 \%$ da população do município.

No mês de julho de 2015, o montante desembolsado pelo governo federal no PBF, nos 42 municípios da AMZOP, foi de $\mathrm{R} \$ \mathrm{R} \$ 2.558 .143,00$ (Dois milhões, quinhentos e cinquenta e oito mil, cento e quarenta e três reais), o que representa um benefício médio (per capita) de $\mathrm{R} \$ 146,78$ (Cento e quarenta e seis reais e setenta e oito centavos), por família.

Os resultados indicam que $17,41 \%$ da população dos municípios da AMZOP, recebe o benefício do $\mathrm{PBF}$, ficando abaixo do percentual médio do Brasil de $21,64 \%$, mas acima dos percentuais apresentados pelos estados do Rio Grande do Sul $(11,04 \%)$, de Santa Catarina $(6,44 \%)$ e do Paraná $(11,20 \%)$.

\subsection{Famílias beneficiadas pelo PBF e IDHM dos municípios}

A figura 3 apresenta o valor do IDHM com as famílias atendidas pelo PBF nos município.

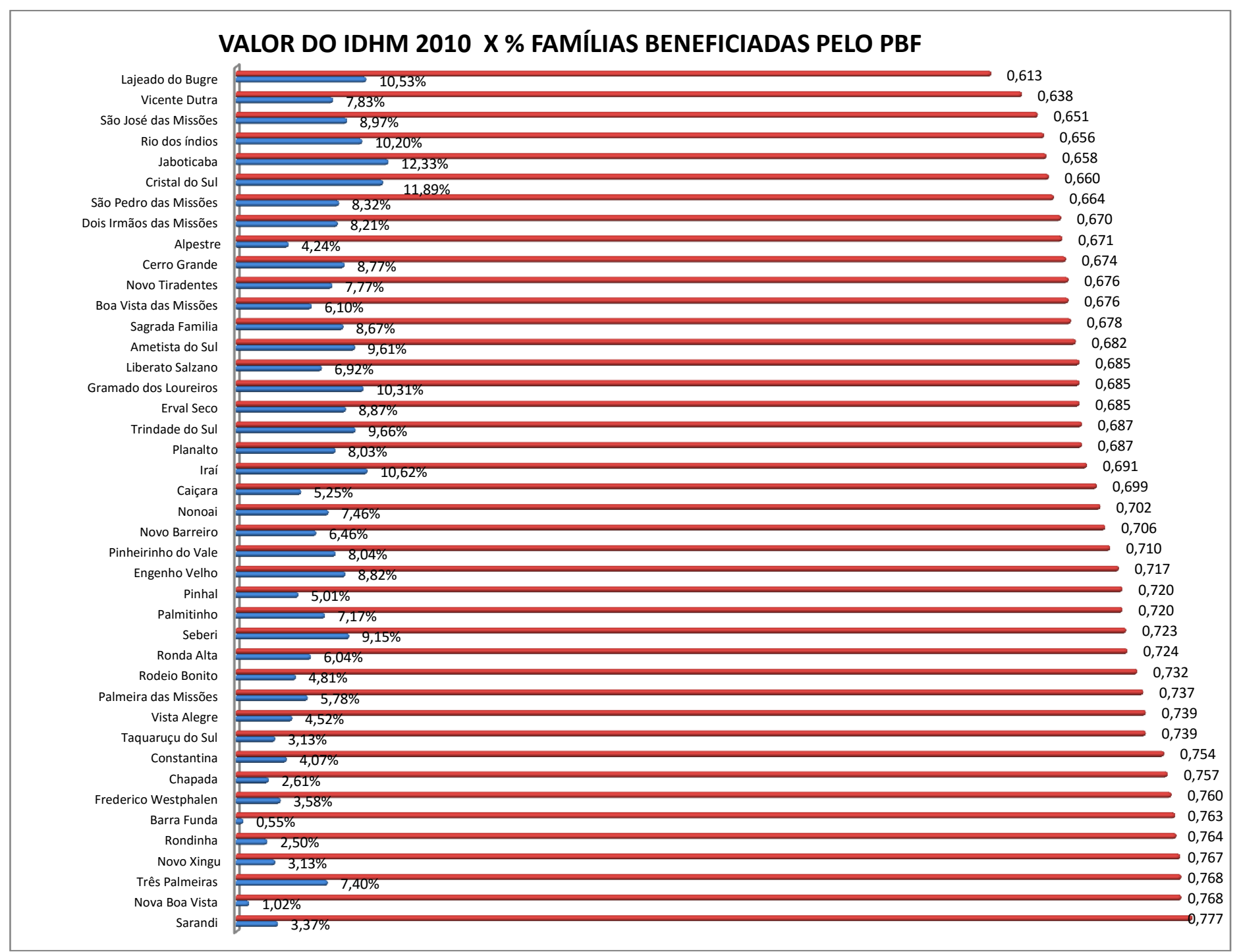

Fonte: Dados da pesquisa. 
Ao relacionar estatisticamente o número de famílias atendidas pelo PBF, com o valor do IDHM dos municípios, os resultados indicam um coeficiente correlação negativa perfeita de $(-0,774)$. Isso demonstra que os municípios que possuem menores valores do IDHM são os que apresentam um número maior de famílias beneficiárias do PBF.

\section{Conclusões}

O PBF é um programa de transferência de renda destinado às famílias em situação de pobreza, com os objetivos de combater a fome e promover a segurança alimentar e nutricional; estimular a emancipação sustentada das famílias que vivem em situação de pobreza e extrema pobreza. De acordo com Santos e Nascimento (2008), o PBF, possui uma representação positiva para as famílias que recebem. Muitas mães relataram que, antes desse programa, não tinham condições de comprar frutas para melhorar a alimentação dos seus filhos.

O presente estudo teve como objetivo, verificar a situação dos municípios que integram a AMZOP, em relação a famílias inscritas no CADÚNICO e famílias beneficiadas pelo PBF, bem como, demonstrar os municípios com maior concentração de famílias em situação de pobreza, beneficiárias do PBF em relação com o IDHM.

Os resultados demonstram que em 32 (trinta e dois) municípios da região da AMZOP, o número de inscritos no CADÚNICO, está acima da média nacional. Ao analisar as faixas de renda per capita denota-se que $17,79 \%$ dos inscritos no CADÚNICO, possuem renda de até $\mathrm{R} \$ 77,00$ por mês, o que se classifica dentro de uma faixa de renda definida como de pobreza e extrema pobreza (ROCHA, 2013, pp. 27-28).

Em relação ao PBF, os resultados indicam que em 20 (vinte) municípios sua população apresenta dependência no recebimento do PBF, acima da média nacional de 21,64\%. Estes municípios apresentam o número de beneficiários do $\mathrm{PBF}$, que varia entre $21,65 \%$ a $32,96 \%$ de sua população.

O município de Jaboticaba é o que possui o maior número de famílias dependentes no recebimento do PBF. São 1355 pessoas de 507 famílias que são beneficiárias do PBF, por outro lado o município de Barra Funda é o município que possui 13 famílias beneficiárias, contemplando apenas 36 pessoas vinculadas.
Ao proceder à relação entre o número de famílias beneficiadas no PBF de cada município com os índices do IDHM, os resultados indicam uma forte correlação negativa. Isso demonstra que os municípios que possuem maior dependência de famílias nos PBF, são os que possuem menores índices de desenvolvimento humano (IDHM).

A inserção de políticas governamentais, de médio e longo prazo, tendo em vista, a capacitação e o treinamento em atividades técnicas, o estímulo de investimentos nas pequenas propriedades rurais e na criação e capitalização de empresas, a criação e o desenvolvimento de cooperativas de produtores, tendo em vista a comercialização dos produtos no mercado em geral ou para órgãos governamentais são algumas alternativas que possibilitam o incremento de renda e gradativamente a diminuição de beneficiários do programa nos municípios com maior população com dependência.

Por outro lado, as condicionalidades estabelecidas pelo $\mathrm{PBF}$, tornam-se importantes, pois exige frequência mínima dos filhos dos beneficiários nas escolas, o que vem a melhorar os níveis educacionais, também exige o comparecimento das crianças dos beneficiários do programa a cumprirem um calendário de vacinação, as gestantes a realizarem consultas de pré-natal e ao puerpério e também incorrer aos serviços de convivência e fortalecimento de vínculos (assistência social). Isso possibilita a frequência mínima dos beneficiários nas escolas, o que eleva os níveis educacionais e a cumprir com calendários de assistência médica e assistência social.

Além do exposto o programa propicia a transferência de renda para regiões mais pobres do Brasil, tornando possível que as famílias saiam da linha da pobreza e consigam fazer girar a economia dessas regiões. Porém o programa apresenta como principal fator limitante a inexistência de prazos de saída dos beneficiários.

Por fim, novos estudos poderão ser realizados, com o objetivo de conhecer a realidade socioeconômica dos municípios com maior e menor dependência de pessoas no PBF. Um estudo também poder-se-ia verificar os motivos (fatores) que levaram muitas famílias a migrarem do PBF. 


\section{Referências}

BRASIL. Constituição da República Federativa do Brasil. Brasília, DF: Senado Federal: Centro Gráfico, 1988. 292 p.

\section{BRASIL. Lei 10.836 de 9 de janeiro de 2004. Cria} o Programa Bolsa Família e dá outras providências. Disponível em: $<$ http://www.planalto.gov.br/ccivil_03/_ato20042006/2004/lei/110.836>.htm. Acesso em: 01 abr. 2015.

BRASIL. Decreto $\mathrm{N}^{\mathbf{0}} \mathbf{6 . 1 3 5}$, de 26 de junho de 2007. Dispõe sobre o Cadastro Único para Programas Sociais do Governo Federal e dá outras providências. Disponível em: http://www.planalto.gov.br/ccivil_03/_ato20072010/2007/decreto/d6135.htm. Acesso em: 13 jul. 2015.

Condicionalidades do Bolsa Família. (2015) Disponível em: <http://www.mds.gov.br/falemds/perguntasfrequentes/bolsa família/condicionalidades/beneficiário/condicion alidades>. Acesso em: 09 jul. 2015.

CUNHA, R. Transferência de Renda com condicionalidade: A experiência do Programa Bolsa Família, In: concepção e gestão da proteção social não contributiva no Brasil. Brasília: Ministério de Desenvolvimento Social e Combate a Fome, UNESCO. 2009.

Formulário principal de cadastramento - Ministério do Desenvolvimento Social e Combate à Fome Cadastro Único para Programas Sociais. Cod 31.442 v.005.

GIL, A. C. Como elaborar projetos de pesquisa. 4. ed. São Paulo: Atlas, 2002.

LEMOS, L.T; RIBEIRO.M.V. As estratégias de manutenção de das famílias durante o período de bloqueio do programa bolsa família devido descumprimento de condicionalidades. Trabalho de conclusão de curso da Faculdade Católica Salesiana do Espírito Santo. 2012. Disponível em:
es.edu.br/fotos/files/AS\%20ESTRATEGIAS_D

E_MANUTENCAO_DAS_FAMILIAS_DURA NTE_O_PERIODO_DE_BLOQUEIO_DO_PR OGRAMA_BOLSA_FAMILIA_DEVIDO_DES CUMPRIMENTO_DE_CONDICIONALIDAD ES.pdf. Acesso em: 04 ago.2015

MDS. Ministério do Desenvolvimento Social e Combate à Fome. Inclusão no Cadastro Único. Disponível em: <http://www.mds.gov.br >. Acesso em: 09 jul. 2015.

MDS. Ministério do Desenvolvimento Social e Combate à Fome. Inclusão no Cadastro Único. Disponível em: $<$ http://www.mds.gov.br/falemds/perguntasfrequentes/bolsa-familia/cadastrounico/beneficiario/cadunico-inclusao>. Acesso em: 09 jul. 2015.

PINTO, N.G.M; CORONEL, D.A;BENDER,R. O programa bolsa família de 2004 a 2010: efeitos do desenvolvimento regional no Brasil e em suas regiões. Qualit@s Revista Eletrônica. Vol.17. $\mathrm{n}^{\circ} 1.2015$.

Portal Transparência Brasil. Disponível em: < http://transparencia.gov.br/>. Acesso em: 09 jul. 2015.

ROCHA, S. Pobreza no Brasil. A evolução de longo prazo (1970-2011). Estudos e Pesquisas, Rio de Janeiro: INAE, n. 492. 2013.

; SÁTYRO, N. O Programa Bolsa Família: desenho institucional, impactos e possibilidades futuras. Rio de Janeiro. Ipea. (Texto para Discussão n. 1424) 2006.

THOMÉ, D. O bolsa família e a social-democracia. Acesso em FGV de bolso. Rio de Janeiro: Editora FGV. 2013.

VERGARA, S.C. Projetos e Relatórios de Pesquisa em Administração. São Paulo: ed. Atlas. 1997.

WEISSHEIMER, M. A. Bolsa familia: Avanços, limites e possibilidades do Programa que esta transformando a vida de milhões de famílias no Brasil. 1. Ed. São Paulo: Editora Fundação Perseu Abramo, 160 p. 2006. 